\title{
Kidney News: Spazio Giovani
}

\section{Cari Colleghi,}

tra le tante novità che partono dal 2012 certamente non ultima è quella che vede riservare uno spazio editoriale dedicato alle attività dei giovani nefrologi e degli specializzandi, ovvero di coloro che iniziano la loro avventura professionale nel mondo nefrologico.

Si è deciso di intitolare tale spazio "Kidney News: Spazio Giovani”. Tale denominazione apre una nuova area dedicata alla trattazione di vari tipi di contributi quali casi clinici, articoli originali, opinioni, esperienze formative, e ancora approfondimenti organizzativi fino a dibattiti trattati da giovani nefrologi.

Sin da questo primo numero del 2012 inizia una collaborazione fortemente voluta dalle parti, che ha l'ambizioso obiettivo di valorizzare le idee, le proposte e le intuizioni dei colleghi più giovani per consentire agli stessi di superare sfide sempre più ardue a livello nazionale; con l'augurio più sincero di raggiungere mete anche a livello internazionale.

Questa rubrica “Kidney News: Spazio Giovani” è perfettamente in linea con il progetto di rinnovamento del giornale che, sempre fedele alla tradizione, si consoliderà con la collaborazione continuativa e crescente con i giovani nefrologi che rappresentano il futuro della "Nefrologia".

Yuri Battaglia e Marco Lombardi 